\title{
The impact of housemate relationships on undergraduate student wellbeing
}

Foulkes, L. ${ }^{1}{ }^{*}$, Reddy, A. ${ }^{1}$, Westbrook, J. ${ }^{1}$, Newbronner, E. ${ }^{2}$, McMillan, D. ${ }^{3}$

${ }^{1}$ Department of Education, University of York, York, UK

${ }^{2}$ Department of Health Sciences, University of York, York, UK

${ }^{3}$ Department of Health Sciences and Hull York Medical School, University of York, York, UK

*Corresponding author. lucy.foulkes@york.ac.uk

\section{Abstract}

Rates of psychological distress in UK undergraduate students are high. The majority of undergraduate students live with same-age peers, and are in a developmental period characterised by changes in social cognition and social relationships. As such, examining the relationship that students have with their housemates may be critical for understanding student wellbeing. In the current study, $\mathrm{N}=90$ undergraduates at universities across the UK took part in an online qualitative study examining the role that housemates play in student wellbeing. Four themes were constructed from the data using inductive qualitative content analysis: Positive relationships stem from constant contact and shared experience; Positive relationships enable a wide range of emotional and practical support; Conflict stems from disrespect; and Poor relationships lead to loneliness, isolation and psychological distress. Together, the themes demonstrate the divergent impact that housemates can have on student wellbeing: they can be a source of immense support or great unhappiness. The findings demonstrate that, to understand wellbeing in UK undergraduates, relationships within student accommodation should be examined.

\section{Keywords}

Undergraduate, university, student, housemates, accommodation, wellbeing 


\section{Introduction}

The number of students declaring a mental health condition when they arrive at university increased five-fold between 2006 and 2015, from 0.4\% to 2\% (Thorley, 2017). Once at university, more students than ever are referring themselves to psychological services: $94 \%$ of higher education institutes reported an increase in referrals from 2006 to 2015 (Thorley, 2017). It is unclear whether the increase in presentations reflect an increase in mental health problems or is a consequence of awareness raising and destigmatising. Either way, rates of distress in this population are evidently high (Akram et al., 2019; Lewis \& Cardwell, 2018); understanding the sources of this distress is therefore critical.

Of the students who started their undergraduate degree in the UK in $2017 / 18,80 \%$ were aged 24 or younger (Mantle, 2019). A recent paper suggests that adolescence, the period of substantive biological and psychological development between childhood and adulthood, occurs between the ages of approximately 10 and 24 (Sawyer, Azzopardi, Wickremarathne, \& Patton, 2018). Most undergraduate students are therefore still in adolescence. To understand the factors that might contribute to psychological wellbeing at this age, the distinct developmental aspects of adolescence must be considered (Duffy et al., 2019; Erb, Renshaw, Short, \& Pollard, 2014). For example, most mental illness develops in this period - the majority (75\%) of all mental disorders begin before the age of 24 (Kessler et al., 2005). This highlights that the undergraduate years are a likely time for psychological distress to manifest, and therefore an important time to study factors that might cause or exacerbate this distress.

A second aspect of adolescence, which is often overlooked in the student mental health literature, is that it is a period of considerable social development (Blakemore \& Mills, 2014; Crone \& Dahl, 2012). At this time, individuals are particularly susceptible to social influence (Foulkes, Leung, Fuhrmann, Knoll, \& Blakemore, 2018; Knoll, Leung, Foulkes, \& Blakemore, 2017; Steinberg \& Monahan, 2007) and are hypersensitive to social exclusion (Sebastian, Viding, Williams, \& Blakemore, 2010). In late adolescence, as at all ages, close social relationships are positively associated with 
wellbeing and negatively associated with symptoms of mental health problems (Bagwell et al., 2005; Miething et al., 2016). As such, understanding the specific role of social factors in undergraduate wellbeing may be particularly relevant.

First-year students around the world adjust better to university, academically and emotionally, when they have social support (Friedlander, Reid, Shupak, \& Cribbie, 2007; Lee, Dickson, Conley, \& Holmbeck, 2014; Tao, Dong, Pratt, Hunsberger, \& Pancer, 2000). Qualitative studies with first-year students highlight the importance of making friends at the start of university (Chow \& Healey, 2008), and that failure to do so can lead to unhappiness and homesickness (Denovan \& Macaskill, 2013). Relationships with flatmates or housemates deserve specific attention, since the majority of undergraduate students live with their peers: of the 41,600 first-year students at UK universities, 70\% live with other students (Knight, 2018). One study interviewed first-year students in the UK who had either completed or dropped out of their first year; the latter reported that accommodation was the key place to establish friendships and that being put in a flat with incompatible others was a major factor in deciding to drop out (Wilcox, Winn, \& Fyvie-Gauld, 2005).

Conflict amongst housemates is common, and can be detrimental to student wellbeing (Dusselier, Dunn, Wang, Shelley II, \& Whalen, 2005; Erb et al., 2014). Noise is a widespread issue, particularly noise from music or partying, and students often feel unwilling or unable to ask their housemates to be quiet (Dusselier et al., 2005; Foulkes, McMillan, \& Gregory, 2019; Walsh, Taylor, \& Brennick, 2018). Anecdotally, arguments about cleaning are common, although only one empirical study (of US college roommates) has explicitly mentioned this (Keup, 2007). Whatever the topic, conflict likely arises because students are living independently for the first time, and each student transfers habits and behaviours from their family home into the new accommodation (Holton, 2016). When these habits and behaviours are at odds with those of other students, some renegotiation or behaviour change may be demanded or required, which can lead to tension and disagreements (Holton, 2016). 
In this qualitative online study, we explored the impact of housemates on wellbeing in UK undergraduate students. This study addressed a number of limitations of the existing research. First, of the studies that have reported positive effects of social support at university, few have explored the role of housemates specifically. Second, studies of social support at university have focussed only on first-year undergraduates and the specific context of the transition to university. However, other year groups are of concern: one study found that subjective wellbeing decreases across three years at university (Bewick, Koutsopoulou, Miles, Slaa, \& Barkham, 2010); another found that second year students had the highest level of psychiatric symptoms as measured by the General Health Questionnaire (Macaskill, 2013). In their second year, most UK students move from university halls to privately rented housing, which often involves a change of housemates (Rugg, Ford, \& Burrows, 2004), and sometimes a third move occurs in the third year (Card \& Thomas, 2018). This shift in accommodation, possibly with new peers, highlights that exploring the impact of housemates on wellbeing should cover the whole duration of the university experience, not just the first year. A final limitation of existing research is that qualitative studies, which enable an in-depth exploration of a phenomenon, have typically been interview studies with correspondingly small sample sizes within a single university (Chow \& Healey, 2008; Denovan \& Macaskill, 2013). Therefore, to overcome these issues, the current study examined specifically the role of housemates in student wellbeing across year groups, with a large sample of students at multiple UK universities. 


\section{Method}

Participants.

Participants $(N=90)$ were UK undergraduate students who lived in shared accommodation with other students in the most recent academic year (data were collected during the summer). The questionnaire was started by 136 participants, but 46 terminated before completion, leaving a final sample of $\mathrm{N}=90$ ( 74 female, 15 male, one did not disclose gender). Participants were aged 18 to 29 (mean=20.47, SD=1.25), with the majority (98\%) aged $19-22 . \mathrm{N}=75$ participants were White British; $\mathrm{N}=15$ reported other ethnicities. Most participants $(\mathrm{N}=85)$ reported attending one of 18 universities in England and Wales ( $\mathrm{N}=5$ chose to not disclose their university), and had just completed their first $(\mathrm{N}=14)$, second $(\mathrm{N}=36)$, third $(\mathrm{N}=33)$ or fourth $(\mathrm{N}=7)$ year of undergraduate study. (Note that specific universities are not listed here in order to protect participant anonymity.) The number of housemates ranged from 1 to 24 (mean=6.38, SD=4.27) and participants had lived with at least one of their current housemates for 1-3 years (mean=1.35,SD=1.09). Participants were studying for 52 different subjects, including science and medicine $(\mathrm{N}=49)$, humanities $(\mathrm{N}=30)$ arts $(\mathrm{N}=2)$ or other $(\mathrm{N}=9)$. Participants were recruited through Twitter and Facebook; posts advertised a study investigating the effects of housemates on student wellbeing, and asked for current undergraduate students who had lived with other students in the most recent academic year.

\section{Ethics.}

Ethical approval was obtained from the first author's departmental ethics committee. There was a possibility that participants with particularly negative experiences with housemates might find it upsetting to take part in the study, so several steps were taken to mitigate this risk. First, the consent form detailed the nature of the study and explicitly stated that those who would find it distressing to describe their relationships with housemates should not consent to taking part. Second, contact details were provided about organisations that offer support for difficult relationships. Third, it was emphasised that participants were free to stop completing the questionnaire whenever they wished. 
All participants were given the option to enter a prize draw to win one of two $f 50$ shopping vouchers; these participants were selected at random once data collection was completed.

\section{Procedure.}

Data were collected using the online survey software Qualtrics. An initial questionnaire of eight open-ended questions was developed to assess respondents' relationship with their housemates and the impact that these relationships had on their wellbeing. This initial questionnaire was piloted on five undergraduate students to assess clarity of questions. Based on this feedback, some minor changes were made. For example, the question 'What do you like most about living with your housemates, if anything?' was changed to 'What do you like most about living with your housemates? If nothing, please expand.' This was done to ensure that respondents who did not have positive experiences with housemates would still describe their experiences in detail. The final questionnaire can be seen in Table 1.

Table 1

Open-ended questions asked of all participants

Q1. How would you describe your relationship with your housemates?

Q2. How did your housemates affect your experience of life at university?

Q3. Are you likely to stay in touch with your housemates? Please explain your answer

Q4. What did you like most about living with your housemates? If nothing, please expand

Q5. What do you wish was different about your housemates or your relationship with them? If nothing, please expand

Q6. In what ways have your housemates helped or supported you? If nothing, please expand

Q7. Have you ever argued with or fallen out with any of your housemates? Please explain your answer

Q8. Have you changed or considered changing your accommodation or university due to issues with your housemates? Please explain your answer 


\section{Analysis.}

The data from the questionnaire were analysed using an inductive qualitative content analysis (Bengtsson, 2016; Hsieh \& Shannon, 2005). In order to maximise transparency, details of all stages of analysis were recorded and are reported in the supplementary materials (Long \& Johnson, 2000); see details below.

In the first step, three authors (LF, AR, JW) individually read all the data and then independently coded the data from the first five participants, during which words or phrases were tagged as potential units of meaning. The three researchers discussed their interpretation at this stage and a list of codes was devised (see Supplementary Table 1 for the initial codes generated by each author). In all qualitative analysis, there is a risk that the researchers' preconceived knowledge of the topic will affect interpretation of the data (Bengtsson, 2016; Erlingsson \& Brysiewicz, 2017). This was pertinent in the current study, as the authors conducting the analysis had their own experience of living with housemates at university. Therefore, this initial triangulation step, in which three researchers coded data independently, was conducted to ensure that all potentially relevant content had been captured and to minimise researcher bias (Castleberry \& Nolen, 2018).

In the second step, the first author (LF) then coded the remainder of the scripts, adding to the list of codes as new ideas emerged (see Supplementary Table 2 for complete list of codes at this stage). In the third, the first author then re-read the original data alongside the list of codes, to ensure that all relevant concepts had been captured and appropriately labelled (no changes occurred at this stage). In the fourth step, the first author then read all extracts captured by the codes and began to construct potential themes. This resulted in an initial thematic map that established a preliminary structure between codes and broader themes. This map was revised after further reading of the codes and extracts, until a final thematic map was determined (see Supplementary Figure 1). 


\section{Results}

Four themes were constructed from the data and are discussed in detail below. The themes highlight the conflicting nature of university housemates: they can be a source of immense support, but also a source of great difficulty and distress. Before describing the themes, some brief quantitative data is presented to demonstrate how many participants had positive compared to negative relationships with their housemates; this is to give context to the qualitative analysis.

Quantitative analysis: How many participants had positive or negative relationships with housemates?

For the first question (see Table 1), participants were asked to describe their relationship with their housemates. Responses to this question were coded into four categories: all positive relationships; all negative relationships; mixed (either positive relationships with some housemates and negative with others, or mixed positive and negative aspects with all housemates); and neutral (cordial relationships but not close). Example quotes and the number of participants in each category are given in Table 2. 
Table 2

Count of participants who reported positive or negative relationships, in response to the question 'How would you describe your relationship with your housemates?'

\begin{tabular}{llll}
\hline Category & $\mathrm{N}$ & $\%$ & Example quote/s \\
\hline All positive & 44 & 49 & 'Amazing, my best friends, feel like family' \\
Mixed & 33 & 37 & 'Bad apart from with one of them'/'Good with most apart \\
& 7 & 8 & 'Very rocky. I'm civil and have tried to maintain some sort \\
All negative & & & of a friendship but have got nothing in return.' \\
& 6 & 7 & 'Cordial. I would say hello but would not hang out socially' \\
Neutral & & &
\end{tabular}

This demonstrates that just under half $(49 \%)$ of participants had exclusively positive relationships with all their housemates, and that the majority (86\%) had at least one positive relationship with a housemate. While the number of participants who had exclusively negative relationships was low (8\%), 44\% participants lived with at least one person with whom they had a negative relationship. A relatively high number of participants $(17 \%)$ reported they had no positive relationships within their accommodation. Below, I describe the themes that explore these relationships in more detail.

\section{Qualitative content analysis}

Four key themes were constructed from the data: Positive relationships stem from constant contact and shared experience; Positive relationships enable a wide range of emotional and practical support; Conflict stems from disrespect; and Poor relationships lead to loneliness, isolation and psychological distress. 
Theme 1: Positive relationships stem from constant contact and shared experience.

A key reported feature of positive housemate relationships was the constant presence of housemates. Many participants reported liking that housemates were 'always there': they were individuals with whom participants could talk, eat and socialise, especially after a long or difficult day at university.

"It made it easier knowing I had close friends to come home to if I ever had a bad day or if I was ever feeling down there was always someone to talk to"

"The thing I liked the most was that there was always someone around that I love and trust. If I needed support or reassurance or even just a break from uni work, they were always there."

"It was super nice to have some company in the mornings and evenings, just some general chitchat so I don't feel alone."

Others liked the frequent entertainment, humour and partying that living with good friends offered ("Going out with them was a lot of fun and we bonded through funny times"). What is clearly special about the university experience is that when housemates are close, they offer a constant, easily accessible source of support and fun. Many reported explicitly that without their housemates, they would feel lonely: that without the constant presence of housemates, university would be an isolating experience. Several participants described their housemates in familial terms ("We call each other our uni family"; "They are like my brothers").

In addition to being a constant presence, housemates were a source of support because everyone was at the same life stage: being away from home, dealing with university work, navigating friendships/relationships and finances. 
"Living with other students was really nice because everyone was going through the same thing."

"[My housemate] helped to support me throughout uni as we spent a lot of time together chatting and exploring how we felt about first year, which made me feel less alone."

"They understand how stressful uni can be so it helps to rant to them."

Theme 2: Positive relationships enable a wide range of emotional and practical support.

In part because of their physical proximity and the sense of shared experience, housemates provided participants with a great deal of support. Some examples of support were clearly practical: housemates let each other in if someone had forgotten their key, for example; others mentioned proofreading each other's essays or discussing assignments together. In other cases, housemates offered practical support as a means of relieving emotional stress, like cooking dinner for someone who was busy with work or having a hard time. Housemates often took on a pseudo-parental role, in which they monitored and supported each other's physical and psychological wellbeing.

"[My housemates] accompanied me to medical professionals when my mental health was particularly bad."

"They supported me through exams when I was really stressed and made sure I was eating and sleeping right."

"We would go to the library together and make sure people were not in their room all day." 
Many other participants reported that housemates were helpful because they offered an opportunity to talk through personal and academic challenges, and to provide emotional support with these. Again, there was a sense that the omnipresence of housemates was helpful: that whenever a participant encountered something difficult, there was always and immediately someone who could offer emotional support; this meant that support was offered for many different issues.

"I constantly went to their rooms for a chat or a hug if I was stressed or upset."

"They have been there for me through everything e.g. times of stress, emotional challenges, personal and family problems."

"We're really close and rely on each other. I go to them with all my issues and they will come to me."

Themes 1 and 2 highlight that positive relationships with housemates can be a great asset to a student's university experience, providing a constant, accessible source of intimacy, entertainment and support. However, by the same token, a lack of closeness to housemates can leave students without these social resources. Across many participants, conflict was common, and this is the topic of the remaining two themes.

Theme 3: Conflict stems from disrespect.

Conflict and disagreement was very common, to varying degrees, across participants. At the core of most conflicts was disrespect for others: a lack of understanding, or a lack of concern, about what was considered reasonable in a shared living space or about how actions affected others. The most frequent sources of conflict were issues with cleanliness, particularly in the kitchen; participants 
reported that old food, used dishes and even vomit was left in shared spaces, sometimes for days. There was often a sense of unfairness, in that participants felt that the responsibility for domestic tasks was not shared evenly:

"One girl never washes up and we all have to clean up after her so it is creating a rift."

"The most difficult thing was buying household items, such as washing up liquid, as no one would want to spend their own money on something for the group. It ended up mostly being the same two of us who bought most things."

"Some people were not taking responsibility for their own mess which caused resentment to those who ended up cleaning it, including me."

A second common source of conflict was noise, often from hosting parties or coming home very late at night. Again, there was a sense that housemates were making noise without due consideration of how this would impact other people in the house. For example, participants reported that housemates did not offer prior warning about parties or ignored requests to reduce noise.

"My housemates... are loud and keep throwing parties in our kitchen without the consent of everyone in the house, often late at night, and not even inviting us."

"Some flatmates were harder to get on with due to them being disrespectful (e.g. having a party and not cleaning it at all or having really loud fights with their significant other at 3am for hours)."

"[My housemate] would listen to music through speakers until 4am most nights. (I had to buy 
earplugs because [they] would just laugh it off)."

Several participants referred to the inevitably of conflict in shared accommodation ("I wish they'd be quieter when they came in after nights out and I wish they cleaned the kitchen - normal housemate stuff"). However, there was an interesting divergence in what happened in the aftermath of a disagreement. Some issues were resolved quickly: participants reported that housemates would talk about the problem, apologise and move on ("We were fine after like two minutes"; "The arguments never last longer than a day and we know that we still love each other"). Others lamented that there had been a lack of communication about disagreements: "I wish they were more open with problems, a large issue was due to a lack in communication and very few of them were open to communication". A third group of participants reported that they tried to discuss issues openly, but found that this then escalated into more serious difficulties and arguments:

"[I] asked them to do simple things like clean dishes etc and then they'd turn it around on me and become manipulative."

"One had a party and did not ask the house, when I asked her about it she didn't say sorry and started saying I was out of order. I felt this was unfair and we argued over that."

"I asked could we all do more to keep the house clean as it was a mess and they all said that I was being controlling and a [expletive]."

For those with the most severe conflicts, there was a serious negative impact on some participants, which is discussed in the final theme. 


\section{Theme 4: Poor relationships lead to loneliness, isolation and psychological distress.}

Participants who were not close to their housemates reported how lonely and isolated this made them feel ("It was like living in a six person house all alone"; "I did feel quite lonely a lot of the time"). Sometimes there was explicit social exclusion, where participants reported being left out of conversations or not invited to social events. For some participants, they were excluded along with one or more other housemates ("The majority of them have a large group that go to the pub and socialise together but there are about five of us not included."). For others, they alone were excluded.

"Sometimes I feel a bit like an outsider because two of them are very close. I can feel quite easily excluded from stuff they do together."

"One housemate in particular would leave me out of things that the other two were automatically included in and instead of being respectful of me in doing so she'd talk about what they were doing without me in front of me."

Interestingly, some participants reported that other housemates had accused them of leaving out others. These participants always reported that these accusations were not accurate, or that the person had chosen to isolate themselves from the group.

"When tensions were high arguments happened constantly over everyone bitching about each other or someone, usually [housemate name], feeling left out, even though they were not."

"There was one girl however who was always sort of an outcast, she didn't have much interest in being close with us other girls." 
"Some people have got very angry thinking they are being left out when they have been isolating themselves from the house."

Some participants reported that their housemates did not attempt to even interact with them ("They provided me no support; some would often not even acknowledge me in the hallway"). For 12 participants $(13 \%)$, relationships had deteriorated to the point where they felt intimidated or uncomfortable in the house, particularly in the communal spaces like the kitchen, which meant they either remained in their room or stayed out of the house altogether. Some participants said they were unable to go into the kitchen because of their housemates drinking or partying in that space; this lack of access to cooking facilities then affected participants' eating habits.

"Sometimes I couldn't eat because people would host parties in the communal kitchen and I could not access my food."

"I felt alone and stressed by common areas and ended up retracting into my room and not having much communication with them as they became a source of stress. Normally when I needed to use the kitchen I would listen if anyone was there and would wait in my room for them to leave. I ended up depending mostly on takeout to avoid the kitchen."

"It's hard to live somewhere you feel uncomfortable so my life at uni consisted of me waking up early and coming home late and eating out a lot. Became pretty unhealthy."

Unsurprisingly, participants reported that these difficult relationships with their housemates negatively affected their psychological wellbeing.

"The poor relationship with [my housemate] was so bad it ruined third year socially. It caused 
me anxiety so bad I was unable to eat in the house. I was in constant fight or flight in there so became underweight as when I tried to swallow food I would gag."

"I became afraid and nervous to be in my own house and had to swap rooms with another housemate so there was a floor between me and [my housemate]."

"Living with a housemate who made my life difficult affected my [university] experience negatively. It made me feel paranoid and unwelcome in my own home and stressed me out, leaving me anxious to go into shared spaces and see [my housemate]."

In this study, participants were explicitly asked whether they had changed or considered changing accommodation due to issues with housemates (see Table 1). Only one participant had officially changed accommodation, with a second staying in a hotel for a period to avoid their housemates. However, 31 participants (34\%) reported that they had considered moving. A number of factors prevented them from doing this: they either thought it wasn't an option at their university, or it was too expensive ("I did consider it due to an especially low occasion which resulted in some negative thoughts, however due to financial reasons I was unable to"). Some felt it was too much effort, particularly when they knew it was a temporary situation ("The stress of having to change close to exams was too much so I decided to stick to the house for a few more months until I moved to my new house") or were concerned that new housemates might be even worse ("Changing accommodation could have made my situation a lot worse-better the devil you know"). Others gave more complex social reasons for feeling unable or unwilling to move accommodation:

"Yes [I considered moving], I have emailed to complain about the noise from parties, but decided that I shouldn't try to change because then people would know that I was the one who tattled, and since these housemates are popular, no one would like me. I decided to just persist 
and be subjected to the noise."

"No [I didn't consider moving] because it would be complicated legally speaking and I would not want to abandon my close friend in the house to fend for herself."

Therefore while many students reported conflict with housemates that made them unhappy, most felt that moving was not an option; instead, they reported needing to live in that environment for the remainder of the academic year. 


\section{Discussion}

In this study, we investigated how housemates affect the wellbeing of UK undergraduate students. Four themes were constructed from the data: Positive relationships stem from constant contact and shared experience; Positive relationships enable a wide range of emotional and practical support; Conflict stems from disrespect; and Poor relationships lead to loneliness, isolation and psychological distress. These themes highlight the divergent impact that housemates can have on undergraduate student wellbeing. The first two themes demonstrate that, when relationships are positive, housemates can be a source of invaluable social support, enhancing wellbeing and the university experience. The latter two themes demonstrate that, when relationships with housemates are poor, students at best feel lonely and at worst feel actively afraid to be in their own home.

The finding that social relationships affect students' experience of university is in line with existing evidence. Several studies have demonstrated that establishing social support is a key predictor of successful adjustment to university life (Friedlander et al., 2007; Lee et al., 2014; Wilcox et al., 2005). However, the current study expands on these existing findings in several ways. First, previous studies have typically focused on first year students, and the initial transition to university as a new environment. In the current study, the majority of participants were in their second or third year; the findings highlights that peer relationships continue to affect adjustment and wellbeing throughout the duration of university.

The current study also focuses specifically on housemates, rather than considering social support more generally — which could encompass friends from courses, teams or clubs. Focusing on housemates is critical, in part because this is the most common and easily accessible context in which students make friends (Wilcox et al., 2005). Focusing on housemates is also important because if these relationships deteriorate, students must then live in a home that can feel hostile and intimidating. Moving to university is a considerable transition point in a young person's life (Duffy et al., 2019), and experiencing both safety and comfort are critical for a place to feel like a home (Smith, 1994). As such, difficulties with housemates are unique because they can prevent students establishing a secure home 
at this vulnerable period of transition. Efforts to support students at university and enhance wellbeing, then, should incorporate efforts to reduce conflict amongst housemates.

The current study provides the first in-depth exploration of the prevalence, nature and consequences of problematic relationships within student housing. Conflict was common: $44 \%$ of participants reported at least one difficult relationship with a housemate, and $17 \%$ reported no positive relationships within their accommodation. Although only one (1\%) participant had moved accommodation because of their housemates, a third (34\%) had considered doing so. This highlights, for the first time to our knowledge, that many undergraduate students are living with people with whom they have difficult relationships.

Conflict largely occurred when one or more housemates behaved in a way that others felt was unreasonable or unfair in shared living spaces. One common source of conflict was the kitchen, typically with respect of cleaning and tidying, but also in terms of sharing cupboard space or using others' food or equipment. The second common source of conflict was noise: either noise of housemates coming back from a night out, or from hosting parties or playing music. Prior to the current study, there had been limited investigation of the nature of conflict in student accommodation. One study in Austria found that students often perceive unfairness in how domestic chores are divided up (Mikula, Freudenthaler, Brennacher-Kroll, \& Brunschko, 1997). Conflict around cleaning chores has been found in shared housing outside of university (Clark, Tuffin, Bowker, \& Frewin, 2018) but not in university settings, to our knowledge. The current study demonstrates that conflict is not only common in student accommodation, but that poorly managed conflict can escalate to the point where individuals do not want to be at home. Considering its potential consequences, future research should further investigate the nature of conflict in student housing and how it might best be deescalated and resolved.

It is important to consider the role of physical layout and building design, particularly communal spaces, when understanding housemate relationships. In the current study, communal spaces (primarily kitchens) were described as either being positive spaces—somewhere to eat and 
chat with close friends—or spaces fraught with difficulty. For participants with difficult housemate relationships, the kitchen became the source of much conflict, either because they argued over keeping the kitchen clean or because people hosted unwanted parties there. In some cases, kitchens became intimidating spaces that participants were afraid to enter. Some existing studies have highlighted the interplay between communal spaces and wellbeing. One study highlighted that deterioration in relationships can lead students to avoiding each other in common spaces, increasing physical isolation (Holton, 2016). A second found that students with en suite rooms and no communal areas had fewer accidental meetings with their housemates, which was associated with poorer relationships and decreased wellbeing (Easterbrook \& Vignoles, 2015). As such, student kitchens should be viewed not simply as a practical space to cook and eat but as a space that reflects the quality of relationships in the household, both positive and negative. The importance of communal spaces, particularly kitchens, should be considered when attempting to resolve student conflict, for example in mediation settings.

The current study raises interesting questions regarding whether anything can be done to ameliorate the suffering caused by poor housemate relationships. Participants who had difficult relationships were rarely in a house that was universally bad; this could be potentially be harnessedfor example, by pastoral staff offering support and mediation—so that positive relationships could be used to buffer the effects of negative ones. Students could be offered more guidance about how to reduce and manage conflict about shared living. If this is unsuccessful, students should be given the option to transfer accommodation without prohibitive financial costs.

For first year students, it is interesting to consider whether anything could be done before they arrive at university that would reduce the risk of conflict in their accommodation. UK undergraduate students do not choose their housemates in their first year of university, but some universities ask questions in advance and attempt to match students on the basis of their answers. For example, some universities ask incoming students about their hobbies, their desire to socialise, their cleanliness and/or their typical bedtime (Rosenbaum, 2018). Of 100 UK universities surveyed, 39 
offered specified quieter flats or blocks, and 17 offered alcohol-free accommodation; some offer online booking where specific rooms can be selected (allowing existing friends to book adjacent rooms, for example; Rosenbaum, 2018). In theory, this could improve compatibility and reduce conflict in student accommodation, but to our knowledge there is not yet empirical data examining this. In addition, matching students in advance on characteristics raises complex questions regarding social engineering and integration (Rosenbaum, 2018). For example, if students of specific religions are more likely to choose alcohol-free accommodation, or if students with mental health conditions choose quiet accommodation, then this may create undesirable and problematic segregation amongst students.

Some limitations of the current study should be noted. First, while the sample size was generous for qualitative data, it is still small when considering the number of undergraduate students in the UK. As such, future studies should examine housemate relationships in a larger sample, one that has been systematically recruited to be as representative as possible. The majority ( $82 \%)$ of the current sample were female; it would be pertinent for future designs to recruit more males to examine whether gender affects experience with housemates. It would also be interesting to explore how aspects of accommodation (e.g. number of housemates) are associated with wellbeing in a quantitative design.

Individual differences in students themselves likely affect how they relate to housemates, but this was not examined in the current study. Future studies could examine whether individual differences in variables such as personality and mental health traits (e.g. anxiety) would affect relationship with housemates, as well as demographic variables such as age and home/international student status. Finally, while the online design meant we could collect data from a large number of students from many institutions, this format meant there was sometimes a lack of depth to participants' answers, which could not be developed as they might in an interview study. As such, it would be valuable to follow up this study with one using interviews or focus groups, to fully explore ideas surrounding housemates and wellbeing. 


\section{Conclusion}

In this study, we explored the relationships that UK undergraduate students have with their housemates, and the impact this has on psychological wellbeing. The themes constructed from the data highlight the divergent effects that housemates can have on the lives of undergraduates. In one

respect, housemates can considerably enhance wellbeing. When a student is close to their housemates, these peers offer an invaluable source of entertainment, friendship and support-a bond that is enabled by their close proximity and strengthened by their shared life experience. In contrast, when relationships are poor, housemates can be a source of great stress and unhappiness. Conflict is common in student houses, often underscored by a lack of respect, and at its worst can mean students feel anxious and intimidated in their own home. Together, the findings demonstrate that housemates can have an extensive impact on undergraduates' university experience, and should be a target when considering how to best support and improve student wellbeing.

\section{Acknowledgements}

This research was supported by a departmental grant to the first author. 


\section{References}

Akram, U., Akram, A., Gardani, M., Ypsilanti, A., McCarty, K., Allen, S., \& Lazuras, L. (2019). The Relationship between Depression and Insomnia Symptoms Amongst a Sample of UK University Students. Sleep Medicine Research, 10(1), 49-53. https://doi.org/10.17241/smr.2019.00332

Bagwell, C. L., Bender, S. E., Andreassi, C. L., Kinoshita, T. L., Montarello, S. A., \& Muller, J. G. (2005). Friendship quality and perceived relationship changes predict psychosocial adjustment in early adulthood. Journal of Social and Personal Relationships, 22(2), 235-254. https://doi.org/10.1177/0265407505050945

Bengtsson, M. (2016). How to plan and perform a qualitative study using content analysis. NursingPlus Open, 2, 8-14. https://doi.org/10.1016/j.npls.2016.01.001

Bewick, B., Koutsopoulou, G., Miles, J., Slaa, E., \& Barkham, M. (2010). Changes in undergraduate students' psychological well-being as they progress through university. Studies in Higher Education, 35(6), 633-645. https://doi.org/10.1080/03075070903216643

Blakemore, S.-J., \& Mills, K. L. (2014). Is Adolescence a Sensitive Period for Sociocultural Processing? Annual Review of Psychology, 65(1), 187-207. https://doi.org/10.1146/annurev-psych010213-115202

Card, P., \& Thomas, H. (2018). Student housing as a learning space. Journal of Geography in Higher Education, 1-15. https://doi.org/10.1080/03098265.2018.1514489

Castleberry, A., \& Nolen, A. (2018). Thematic analysis of qualitative research data: Is it as easy as it sounds? Currents in Pharmacy Teaching and Learning, 10(6), 807-815. https://doi.org/10.1016/j.cptl.2018.03.019

Chow, K., \& Healey, M. (2008). Place attachment and place identity: First-year undergraduates making the transition from home to university. Journal of Environmental Psychology, 28(4), 362-372. https://doi.org/10.1016/j.jenvp.2008.02.011 
Clark, V., Tuffin, K., Bowker, N., \& Frewin, K. (2018). A fine balance: A review of shared housing among young adults. Social and Personality Psychology Compass, 12(10), e12415. https://doi.org/10.1111/spc3.12415

Crone, E. A., \& Dahl, R. E. (2012). Understanding adolescence as a period of social-affective engagement and goal flexibility. Nature Reviews Neuroscience, 13(9), 636-650. https://doi.org/10.1038/nrn3313

Denovan, A., \& Macaskill, A. (2013). An interpretative phenomenological analysis of stress and coping in first year undergraduates. British Educational Research Journal, 39(6), 1002-1024. https://doi.org/10.1002/berj.3019

Duffy, A., Saunders, K. E. A., Malhi, G. S., Patten, S., Cipriani, A., McNevin, S. H., ... Geddes, J. (2019). Mental health care for university students: A way forward? The Lancet Psychiatry. https://doi.org/10.1016/S2215-0366(19)30275-5

Dusselier, L., Dunn, B., Wang, Y., Shelley II, M. C., \& Whalen, D. F. (2005). Personal, Health, Academic, and Environmental Predictors of Stress for Residence Hall Students. Journal of American College Health, 54(1), 15-24. https://doi.org/10.3200/JACH.54.1.15-24

Easterbrook, M. J., \& Vignoles, V. L. (2015). When friendship formation goes down the toilet: Design features of shared accommodation influence interpersonal bonds and well-being. British Journal of Social Psychology, 54(1), 125-139. https://doi.org/10.1111/bjso.12062

Erb, S. E., Renshaw, K. D., Short, J. L., \& Pollard, J. W. (2014). The Importance of College Roommate Relationships: A Review and Systemic Conceptualization. Journal of Student Affairs Research and Practice, 51(1), 43-55. https://doi.org/10.1515/jsarp-2014-0004

Erlingsson, C., \& Brysiewicz, P. (2017). A hands-on guide to doing content analysis. African Journal of Emergency Medicine, 7(3), 93-99. https://doi.org/10.1016/j.afjem.2017.08.001

Foulkes, L., McMillan, D., \& Gregory, A. M. (2019). A bad night's sleep on campus: An interview study of first-year university students with poor sleep quality. Sleep Health, 5(3), 280-287. https://doi.org/10.1016/j.sleh.2019.01.003 
Foulkes, Lucy, Leung, J. T., Fuhrmann, D., Knoll, L. J., \& Blakemore, S.-J. (2018). Age differences in the prosocial influence effect. Developmental Science, 21(6), e12666.

https://doi.org/10.1111/desc.12666

Friedlander, L. J., Reid, G. J., Shupak, N., \& Cribbie, R. (2007). Social Support, Self-Esteem, and Stress as Predictors of Adjustment to University Among First-Year Undergraduates. Journal of College Student Development, 48(3), 259-274. https://doi.org/10.1353/csd.2007.0024

Holton, M. (2016). Living together in student accommodation: Performances, boundaries and homemaking: The geographies of student accommodation. Area, 48(1), 57-63. https://doi.org/10.1111/area.12226

Hsieh, H.-F., \& Shannon, S. E. (2005). Three Approaches to Qualitative Content Analysis. Qualitative Health Research, 15(9), 1277-1288. https://doi.org/10.1177/1049732305276687

Kessler, R. C., Berglund, P., Demler, O., Jin, R., Merikangas, K. R., \& Walters, E. E. (2005). Lifetime Prevalence and Age-of-Onset Distributions of DSM-IV Disorders in the National Comorbidity Survey Replication. Archives of General Psychiatry, 62(6), 593. https://doi.org/10.1001/archpsyc.62.6.593

Keup, J. R. (2007). Great Expectations and the Ultimate Reality Check: Voices of Students During the Transition from High School to College. Journal of Student Affairs Research and Practice, 44(1). https://doi.org/10.2202/1949-6605.1752

Knight, O. (2018). Student Accommodation Survey 2018/19. Knight Frank/UCAS.

Knoll, L. J., Leung, J. T., Foulkes, L., \& Blakemore, S.-J. (2017). Age-related differences in social influence on risk perception depend on the direction of influence. Journal of Adolescence, 60, 53-63. https://doi.org/10.1016/j.adolescence.2017.07.002

Lee, C., Dickson, D. A., Conley, C. S., \& Holmbeck, G. N. (2014). A Closer Look at Self-Esteem, Perceived Social Support, and Coping Strategy: A Prospective Study of Depressive Symptomatology Across the Transition to College. Journal of Social and Clinical Psychology, 33(6), 560-585. https://doi.org/10.1521/jscp.2014.33.6.560 
Lewis, E. G., \& Cardwell, J. M. (2018). A comparative study of mental health and wellbeing among UK students on professional degree programmes. Journal of Further and Higher Education, 113. https://doi.org/10.1080/0309877X.2018.1471125

Long, T., \& Johnson, M. (2000). Rigour, reliability and validity in qualitative research. Clinical Effectiveness in Nursing, 4(1), 30-37. https://doi.org/10.1054/cein.2000.0106

Macaskill, A. (2013). The mental health of university students in the United Kingdom. British Journal of Guidance \& Counselling, 41(4), 426-441. https://doi.org/10.1080/03069885.2012.743110 Mantle, R. (2019). Higher Education Student Statistics: UK, 2017/18. HESA.

Miething, A., Almquist, Y. B., Östberg, V., Rostila, M., Edling, C., \& Rydgren, J. (2016). Friendship networks and psychological well-being from late adolescence to young adulthood: A genderspecific structural equation modeling approach. BMC Psychology, 4(1). https://doi.org/10.1186/s40359-016-0143-2

Mikula, G., Freudenthaler, H. H., Brennacher-Kroll, S., \& Brunschko, B. (1997). Division of Labor in Student Households: Gender Inequality, Perceived Justice, and Satisfaction. Basic and Applied Social Psychology, 19(3), 275-289. https://doi.org/10.1207/s15324834basp1903_1

Rosenbaum, M. (2018). University friends: By chance or by design? BBC.

Rugg, J., Ford, J., \& Burrows, R. (2004). Housing advantage? The role of student renting in the constitution of housing biographies in the United Kingdom. Journal of Youth Studies, 7(1), 19-34. https://doi.org/10.1080/1367626042000209930

Sawyer, S. M., Azzopardi, P. S., Wickremarathne, D., \& Patton, G. C. (2018). The age of adolescence. The Lancet Child \& Adolescent Health, 2(3), 223-228. https://doi.org/10.1016/S2352$4642(18) 30022-1$

Sebastian, C., Viding, E., Williams, K. D., \& Blakemore, S.-J. (2010). Social brain development and the affective consequences of ostracism in adolescence. Brain and Cognition, 72(1), 134-145. https://doi.org/10.1016/j.bandc.2009.06.008 
Smith, S. G. (1994). The essential qualities of a home. Journal of Environmental Psychology, 14(1), 31-46. https://doi.org/10.1016/S0272-4944(05)80196-3

Steinberg, L., \& Monahan, K. C. (2007). Age differences in resistance to peer influence. Developmental Psychology, 43(6), 1531-1543. https://doi.org/10.1037/0012-1649.43.6.1531

Tao, S., Dong, Q., Pratt, M. W., Hunsberger, B., \& Pancer, S. M. (2000). Social Support: Relations to Coping and Adjustment During the Transition to University in the People's Republic of China. Journal of Adolescent Research, 15(1), 123-144. https://doi.org/10.1177/0743558400151007

Thorley, C. (2017). Not by degrees: Improving student health in the UK's universities. Institute for Public Policy Research.

Walsh, A., Taylor, C., \& Brennick, D. (2018). Factors That Influence Campus Dwelling University Students' Facility to Practice Healthy Living Guidelines. Canadian Journal of Nursing Research, 50(2), 57-63. https://doi.org/10.1177/0844562117747434

Wilcox, P., Winn, S., \& Fyvie-Gauld, M. (2005). 'It was nothing to do with the university, it was just the people': The role of social support in the first-year experience of higher education. Studies in Higher Education, 30(6), 707-722. https://doi.org/10.1080/03075070500340036 